limited by their specific range of skill and their professional role. Not all forms of protection count as medical care. While, for example, a doctor has a responsibility to protect Salman Rushdie from the consequences of an attempt on his life, he or she has no responsibility to protect him from that attack. Others, of course, do.

DONALD EVANS

Centre for Philosophy and Health Care,

University College,

Swansea SA2 8AW

1 Foreman DM, Farsides C. Ethical use of covert videoing techniques in detecting Munchausen syndrome by proxy. techniques in detecting Munchausen

2 Gerard L. Video traps catch abuse of children by parents. Observer 1993 September 26:9.

3 Samuels MP, McClaughlin W, Jacobson RR, Poets CF, Southall DP. Fourteen cases of imposed upper airway obstruction. Arch Dis Child 1992;67:162-70.

\section{Publishing the findings of clinical research}

EDrroR,-A J Munro' and Andrew Herxheimer ${ }^{2}$ raised important issues about the publication and dissemination of the results of clinical research. For universities the release of results of research into the public domain is a condition of their status as educational charities. Universities are exempt charities whose primary purpose is the advancement of education through teaching and research. There must be some benefit to the public if the advancement of education is to be charitable. Research undertaken for the private benefit of a sponsor, where the results are not finally released into the public domain, is outside the charitable status of the institution.

Universities recognise that commercial sponsors of research may need time to gain some advantage over competitors by delaying publication of results. This is why the Committee of Vice Chancellors and Principals of the Universities of the United Kingdom has recommended that universities should allow sponsors the right to delay publication for a specified period, normally not more than 12 months. A longer delay of two years or, at the very most, three years may be appropriate in exceptional circumstances, but only if the sponsor presents a compelling case and this is agreed with the researchers concerned.

A M A POWELL

Committee of Vice Chancellors and Principals of the Universities of the UK, London WC1H 9EZ

1 Munro AJ. Publishing the findings of clinical research. $B M F$ 1993;307:1340-1. (20 November.)

2 Herxheimer A. Publishing the results of sponsored clinical research. $B M f 1$ 1993;307:1296-7. (20 November.)

3 Committee of Vice Chancellors and Principals of the Universities of the UK. Sponsored university research: recommendations and of the UK. Sponsored university research: recomm
guidance on contract issues. London: CVCP, 1992.

\section{Dutch model of maternity care}

\section{May not suit Britain}

EDrroR,-In her comprehensive paper Christina Oppenheimer looked at aspects of the Dutch model of maternity care of relevance to establishing care led by midwives in Britain. ${ }^{1}$ The internal market in the health services in Britain, inspired by a free market ideology, seems to be fundamentally different from the Dutch way of organising the provision of services. In the Netherlands state intervention limits competition between general practitioners and midwives, the weakest competitors in the maternity services, through a reimbursement system. Likewise the competition between providers of primary care and obstetricians is limited through national selection criteria that favour midwives and general practitioners for low and medium risk deliveries. The Dutch system ensures midwives a market share. It also ensures, in contrast to the British system, that women - whether at a low, medium, or high riskreceive care in the appropriate place and from the appropriate birth attendant. The Dutch government recognises that its system is cheaper than that of its neighbours. Consequently, support of midwives and home births is strong and representative of support for a wider policy to move care out of the hospital into the home. ${ }^{2}$

Furthermore, introducing midwifery led care in Britain would be difficult without some form of help for midwives, such as that given by maternity home care assistants (maternity aids) in the Netherlands. These assistants help midwives during home births, provide much of the postnatal care, and thus free midwives to attend more deliveries while also strengthening midwives' sense of professional autonomy. $^{3}$ They are an integral part of the provision of maternity care and facilitate home deliveries and deliveries necessitating only a short stay in hospital. At present, similar support for new mothers in Britain is limited to exceptional cases-for example, mothers with triplets or quadruplets-and the assigned home helps seldom have formal training. ${ }^{4}$ While supporting the changes towards more midwifery led care, I would emphasise that you have to be careful in picking out desirable aspects of maternity care in the Netherlands and assuming that they can be easily transferred into the different British framework.

EDWIN R VAN TEILINGEN

Centre for HIV/AIDS and Drug Studies,

City Hospital,

Edinburgh EH10 5SB

1 Oppenheimer C. Organising midwifery led care in the Netherlands. BM7 1993:307:1400-2. (27 November.)

2 Simons $\mathrm{H}$. De verloskundige: spil of speelbal? In: van der Hulst LAM, ed. De vroedrouw, de spil van de verloskunde. Bilthoven: Catherina Schrader Stichting, 1991:20.

3 Teijlingen van $E$. The profession of maternity home care assistan and its significance for the Dutch midwifery profession. Int Nurs Stud 1990;27:355-66.

4 Price FV. Who helps? In: Botting BJ, Macfarlane AJ, Price FV. Three, four or more: a study of triplets and higher order birth. London: HMSO, 1990.

\section{Dutch model limits choice}

EDITOR,-A paper ${ }^{1}$ and an editorial ${ }^{2}$ have commented favourably on low risk care led by midwives in the Netherlands, and the editorial suggested that this might reduce the number of unnecessary caesarean sections performed in Britain for fear of litigation.

The main reason for the difference between caesarean section rates in Britain and the Netherlands is that women's choice is denied in the Netherlands because the midwife decides when and to whom to refer the woman when problems arise, whereas in Britain women can opt for an elective caesrean section after discussion with their obstetrician-for example, because of a previous difficult vaginal delivery, breech presentation, etc. One of us is Dutch, and his sister had a three hour second stage in the Netherlands without being referred to an obstetrician despite her repeated requests for this. Informed choice is one of the important elements of the Cumberlege report, ${ }^{3}$ and obstetricians are concerned that this system may result in more emergency obstetrics. Similarly, active management of labour achieves even lower rates of caesarean section, ${ }^{4}$ but it has not been widely adopted in Britain probably because it is also perceived as restricting women's choice.

Emergency obstetrics is associated with a poorer outcome for babies and to some extent for mothers. There is no system of routine audit of obstetric care in the Netherlands, whereas Britain has longstanding traditions of audit (perinatal mortality meetings, the confidential inquiry into maternal deaths). Both the paper and the editorial quoted the Wormerveer study in the Netherlands, of 8055 births during 1969-83, which showed an unacceptably high perinatal mortality among babies transferred to obstetricians by midwives. In Britain the risks of caesarean section to the mother are greatest after an emergency procedure, maternal mortality being similar after elective caesarean section and vaginal delivery.5 The British confidential inquiry for $1985-7$ noted that inexperience or the decreasing frequency of problems resulted in substandard care and that greater involvement of consultants was necessary for the best possible care to be achieved.'

Finally, midwives in the Netherlands are paid according to the number of deliveries they conduct, and $30 \%$ of the population has to take out private insurance to pay for this system (personal communication, Dutch Ministry of Health). The British, cost effective system already offers women the widest choice in childbirth.

LAWRENCE MASCARENHAS FRANK BIERVLIET HARRY GEE MARTIN WHITTLE

Academic Department of Obstetrics and Gynaecology,

University of Birmingham,

Birmingham Maternity Hospital,

Birmingham B15 2TG

1 Oppenheimer C. Organising midwifery led care in the Netherlands. $B M \Im$ 1993;307:1400-2. (27 November.)

Treffers PE, Pel $M$. The rising trend for caesarean births. $B M F$ 1993;307:1017-8. (23 October.)

3 House of Commons Select Committee on Health. Report on maternity services: list of recommendations and conclusions. London: HMSO, 1992. (House of Commons paper 29-1.)

4 Lopez-Zeno JA, Peaceman AM, Adashek JA, Socol ML. A controlled trial of a program for the active management of controlled trial of a program for the

5 Reports on confidential enquiries into maternal deaths in England and Wales 1982-84 and in the UK 1985-87. London: HMSO, 1989, 1991

\section{Confidentiality, contraception, and young people}

EDrToR,-The recent "guidelines" to doctors" referred to by Gabriel Scally ${ }^{2}$ perpetuate the myth that most underage girls obtain contraceptives from family planning clinics.

Nine years ago a survey of general practitioners revealed that doctors were providing contraceptives to between 2-12 girls a year. ${ }^{3}$ On a national level this meant that, at the very least, 60000 schoolgirls (one in six) were being prescribed the pill by their general practitioners, at a time when only 18000 were attending family planning clinics.

My experience as a parent of schoolage children and as a counsellor with a national pregnancy care charity is that multiple sexual partners and the incidence of sexual infections are now common among 14 and 15 year old girls. And just as before, the great majority of these girls have been prescribed the pill by their general practitioners.

Gabriel Scally and the authors of the guidelines offer no solution to this deteriorating situation other than to urge general practitioners to make themselves even more easily available to the young, and to warn doctors that they may face disciplinary proceedings if they break confidentiality with their young patients. This means keeping as much information as possible secret from parents, especially those who might raise objections to underage sex.

The adverse reaction of the media to these guidelines is indicative of a general feeling that the medical profession has gone well beyond its brief and is now attempting to ride roughshod over the legitimate rights and responsibilities of parents in the upbringing of their children. If confusion now reigns, it is the fault of those high profile organisations, who seem to regard parents as irrational obstacles blocking the path of childrens' uninhibited sexual freedom. Two quotations from the 